\title{
Augmented Reality and the Enhancement of Cultural Heritage: the Case of Palazzo Mocenigo in Padua
}

\author{
Antonio Calandriello
}

\section{Abstract}

Da palazzi nobiliari a sedi universitarie: nuovi modelli di studio e rappresentazione del patrimonio architettonico dell'Università di Padova is the large project which includes the study presented. The aim of the research is to investigate the virtual methods of access and enhancement of the Palazzo Mocenigo Belloni Battagia in Via Sant'Eufemia in Padua. The use of ICT (Information and Communications Technology) is increasingly applied in the cultural heritage sector, especially in the context of museums, in order to increase their inclusiveness and raise the level of use. By exploiting these technologies and applying them to the case at issue, we will try to give visitors the opportunity to virtually see a building closed to the public. Inside Palazzo Mocenigo preserves precious frescoed halls, dating back to the Renaissance period in which the building was one of the major cultural centers of Padua.

Keywords

virtual reality, augmented reality, cultural heritage, virtualization, enhancement.

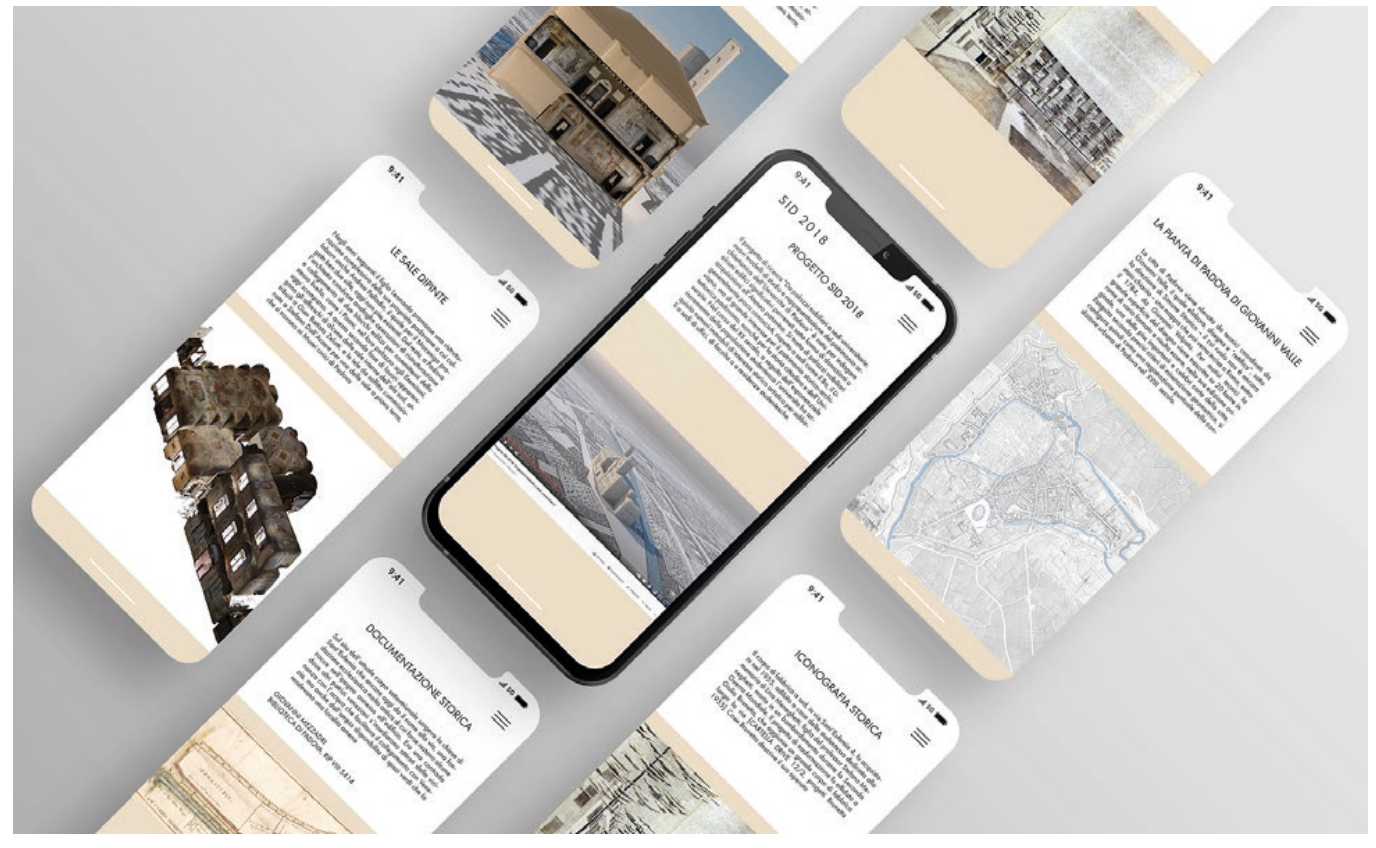


The research project Da palazzi nobiliari a sedi universitarie: nuovi modelli di studio e rappresentazione del patrimonio architettonico dell'Università di Padova [I] was created to investigate some significant buildings received in the form of donations or acquisitions to the University of Padua. These are generally little-known noble palaces, compared to sites such as Palazzo Bo, Palazzo Liviano, but of great interest for the Paduan historical-architectural heritage, as well as for the history of the city and University. During the twentieth century, following the exponential increase in the student population, the university acquired real estate numbers of historical and artistic interest to use them as offices, faculties or student residences. Four buildings of particular importance have been identified in the project: Palazzo Contarini in Via San Massimo, Palazzo Selvatico Luzzato Dina in Via delVescovado, Palazzo Sala in Via San Francesco and Palazzo Mocenigo Belloni Battagia in Via Sant'Eufemia.

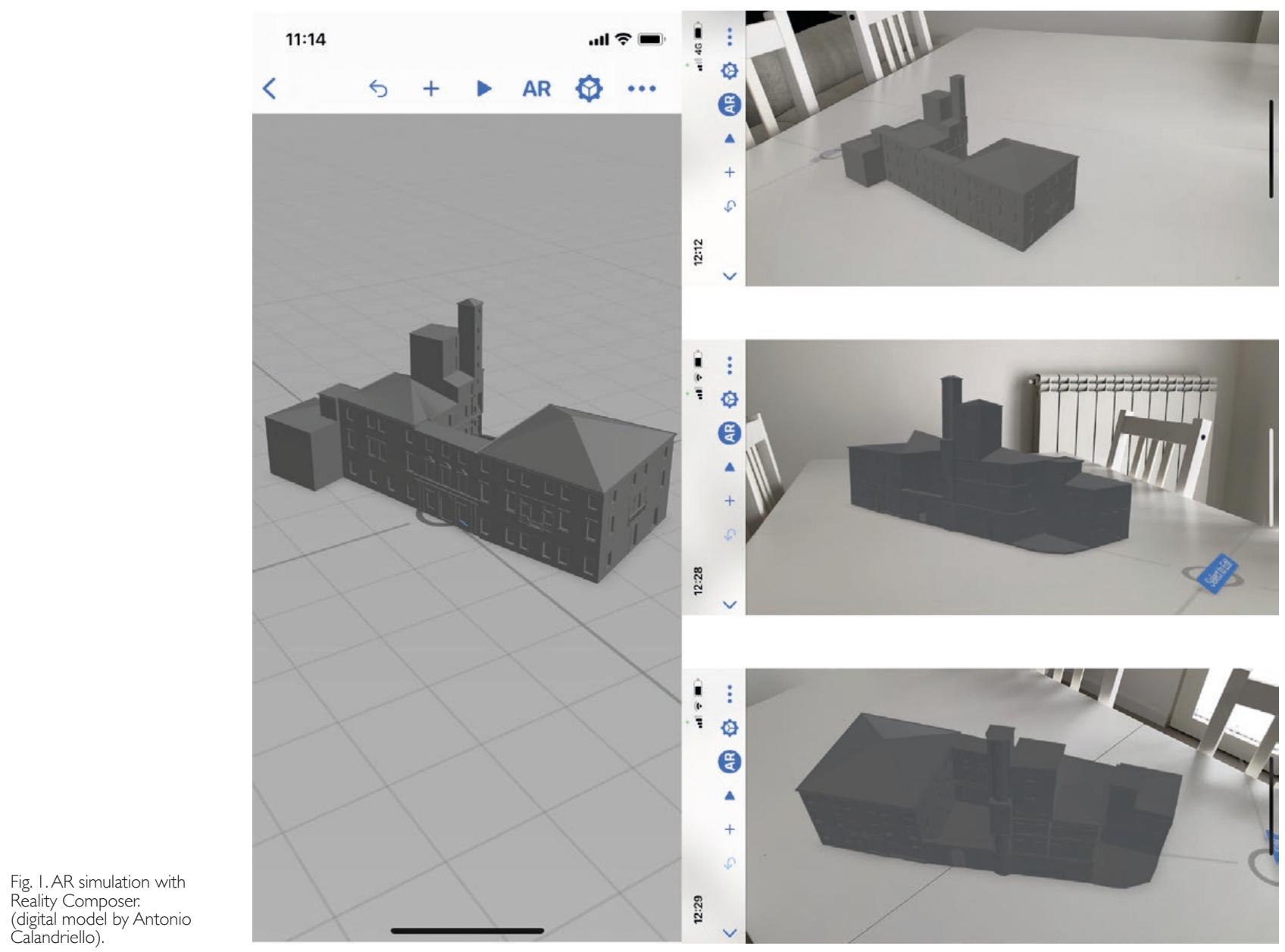

As it appears today, Palazzo Mocenigo is the result of the unification of two distinct structures, built at least in the fifteenth century but profoundly modified, and then connected between the sixteenth and seventeenth centuries. On the site of the current northern body stood the church of Sant'Eufemia which still today gives its name to the street, a very old ecclesiastical foundation. Some traces may remain in the hypogeum attached to the building. It was a city quarter where other Venetian patricians settled, attracted by the proximity to the water that facilitated the connection with Venice, but also by the wide availability of green spaces that made it a pleasant location.

The history of Mocenigo consists of several successive acquisitions, expansions and a restructuring, promoted by Leonardo Mocenigo son of Antonio, which took place in the second half of the sixteenth century. The frescoes in some of the internal rooms of the souther wing - attributed to Gian Battista Zelotti (I526-1578) -, and the ceiling paintings 
commissioned to Stefano Dall'Arzere (1515-1575) for one of the rooms on the ground floor - that are now in the Civic Museums of Padua -, belong to this second phase of the work. From this moment Palazzo Mocenigo became a reference cultural center for the city. The building, now owned by the Belloni family, underwent further works in the first half of the seventeenth century, and other rooms were frescoed by Daniel Van Der Dyck (16101670). The building as it reaches us today is the result of further changes by successive families and in 1955 it was finally used as a residence for students in memory of Lina Meneghetti. The project was entrusted to Giulio Brunetta (1906-1978) who, in addition to the internal adaptation changes of Palazzo Mocenigo itself, adds a further body of the building. In 1960, the University of Padua also bought Palazzo Mocenigo building, which together with the Brunetta building, has been closed to the public since 2012 following the earthquake in Emilia Romagna.

Fig. 2. Hypothesis of tion with smartphone and Google Daydream View. The VR mage shows one hall of Palazzo Mocenigo

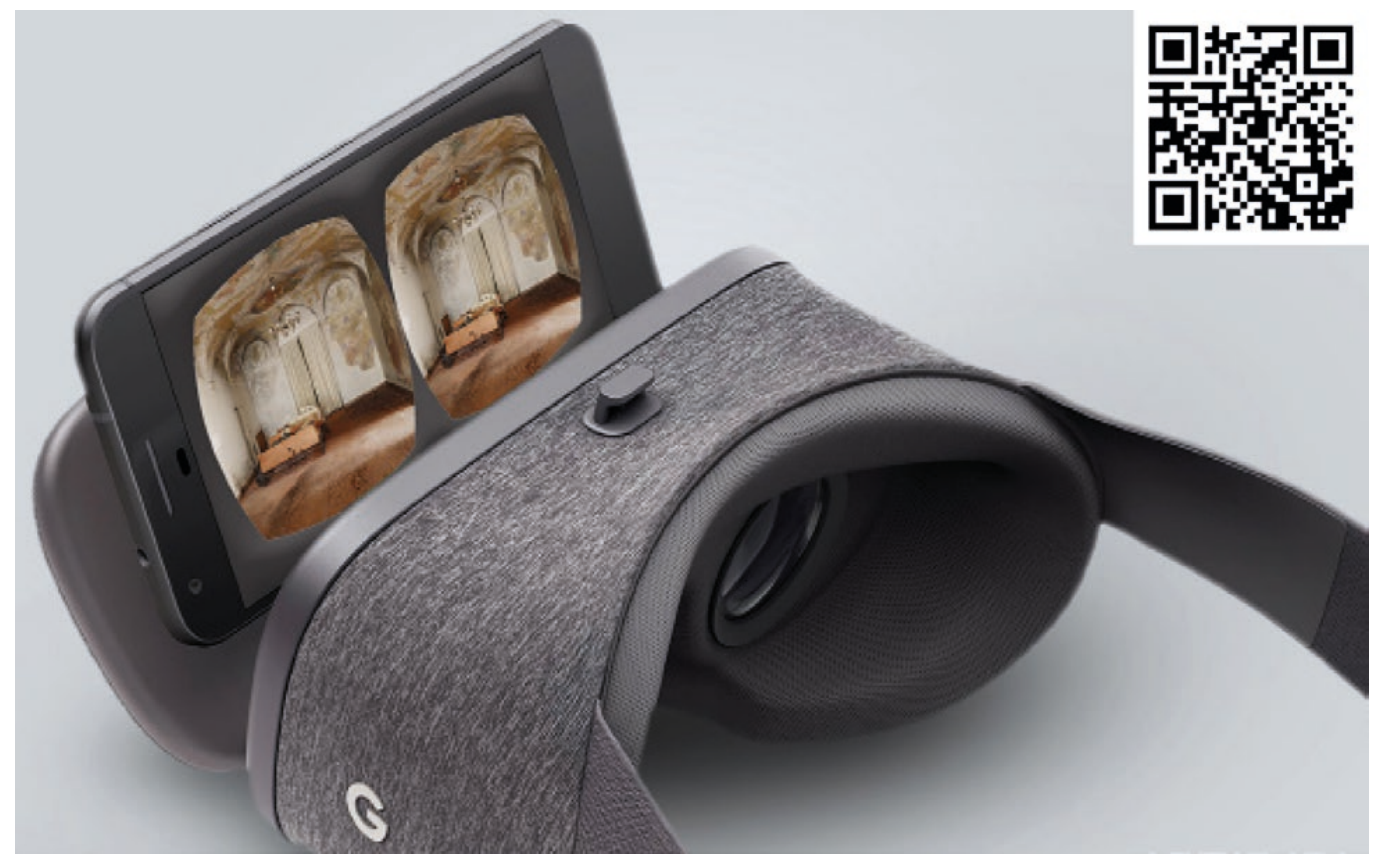

In the case in question, taking advantage of current digital technologies, also borrowed from other sectors that differ from that of cultural heritage, an attempt is made to offer a solution to the impossibility of visiting the property and at the same time, should it reopen the doors to public, offer an increased level of use. Within this process of enhancement it is necessary to underline how the use of ICT (Information and Communications Technology) not only allows a higher degree of use - enhancing the tangible and intangible - and improving social inclusion, but is also able to play an important role also in the conservation of the asset. If we consider the process behind an enhancement project, we will note that this involves an enormous acquisition of data - often of a multidisciplinary nature - which returns a photograph of the current state, both from the point of view of the conservation of the property and of the-state-of-the-art connected to it. It is in this phase that the digitization of the documents that are acquired and processed in order to be adequately disclosed takes place. The study for the enhancement of Palazzo Mocenigo was designed using different digital applications and wants to be paradigmatic also for the other buildings that are part of the key project. Technologies used and intended to be used include virtual reality (VR), augmented reality $(A R)$, video production and application development.

VR can have different levels of interaction, a passive one in which the user 'moves' and another one extremely interactive that gives him the opportunity to interact with space and virtual objects. In the specific case, as will be seen later, we focus on a less advanced level. Augmented reality is a technology that allows you to view additional information in real 
time through an overlap between real and virtual elements (dynamic audiovisual content, 3D animations, films). Through special markers and a device, the real image is enriched with features and information that integrate and complete it.

The video production, on the other hand, allows an informative experience through more traditional channels, but at the same time it was the starting point for some of the immersive experiences listed above.

In order for augmented reality and virtual reality applications to work, it is necessary to create digital content to be subsequently transferred into the various software and applications. The first step was to create a virtual clone of Palazzo Mocenigo, this happened in two ways: with a digital photogrammetric survey and with 3D modeling. The digital photogrammetric survey mainly concerned the internal environments - the halls richly decorated with frescoes showing forest scenes with a Flemish taste and the rooms with suggestive painted architectural perspectives - were detected through high-resolution photographs, respecting the criteria of overlapping and spatial distribution dictated by 'structures from motion' software [2]. Particular attention was paid to continuously detecting the interior of the building, focusing on the connections between one environment and another. This approach made it possible to return a unique model of the frescoed rooms and the connecting rooms with the certainty that all the rooms were perfectly oriented and scaled with respect to the others. The information previously acquired and contained in the images of the passage rooms, used simultaneously in different chunks of Agisoft Metashape, made it possible to automatically align the different models of the individual rooms (Workflow> Align Chunks> (Method) Camera Based). At the end of all the various phases for the production of the mesh model and its texture, this was exported to be then combined with the virtual clones of Palazzo Mocenigo.

The digital models of the entire building were created through the use of historical documentation as regards the one that shows the formal conformation of the building in the mid-16th century, while for the current state it was based on the digital photogrammetric survey and current documentation. The three-dimensional models, which form the common basis of the various declinations of the enhancement project, were subsequently used in different ways.

The structure of the multimedia project of Palazzo Mocenigo foresees as a first output is the creation a totem that will be located in front of the building itself and that represents the 'stargate' for accessing multimedia contents that are recalled and displayed on their devices by scanning of specific QR codes.

A first QR code offers the possibility to view a video that tells the story of the building, its historical evolution and the transformations it has undergone in relation to the urban context. Paying particular attention to showing what it is not possible to see today, revealing the contents of the internal rooms and passively guiding the viewer inside and outside the building, both in its current configuration and in that of the sixteenth century.

A second tag allows you to download an application that contains a series of multimedia contents, including interactive ones. The application provides that the collection of scientific and educational material is arranged by simple accumulation, starting with the most generic information materials and then descending, based on the user's needs, into a series of increasingly specialized information. Through a 'hamburger' menu it is possible to access the different sections that include the historical documents of the land registry, the State Archives of Padua and Venice, the historical information of the building and its transformations over the centuries, the building at the time of residence student, the $360^{\circ}$ virtual tours of the various frescoed rooms, the historical information connected to them, and finally the building in augmented reality. Some of these experiences, as in the case of $360^{\circ}$ virtual tours and the building in augmented reality, can be recalled individually by framing other special QR Codes placed on the entrance totem with your device.

The idea is not to bind the user to necessarily download an application, but to equally use part of the multimedia content made available on online platforms such as Momento360 [3] or to use applications already present in their device as in the case of RealityComposer or ARCore, respectively for iOS and Android platforms. The models of Palazzo Mocenigo 
that should be shared on an opensource platform such as Sketchfab [4] and subsequently displayed directly in AR on their devices. The models created for augmented reality allow you to view the formal and distributive aspects of the building and the arrangement of the frescoed rooms in the two reference periods: at present and in the configuration in the sixteenth century (fig. I).

The virtual tours have been designed to allow the user to mainly explore the interior of the building. Each $360^{\circ}$ render allows you to explore the interior of the rooms in an immersive and interactive way (fig. 2). Thanks to tags placed on the different points of interest, the user can receive information about the paintings or simply move from one environment to another. The information may be of a different nature, from information about the author, the construction, the construction technique to more interpretative ones, such as for the study of architectural perspectives. This last case would represent the maximum expression of the potential of virtual reality applied to the field of Cultural Heritage. The user would find himself immersed in a completely artificial space that arises from the restitution of the architectures painted on the vaults and on the walls of the rooms. There would therefore be not only the possibility of visiting an inaccessible physical space, that of the rooms of Palazzo Mocenigo, but the possibility of finding oneself even in an different dimension, the one depicted in perspective on the walls and vaults of the building itself.

\section{Notes}

[I] Born to experiment new ways of studying, narrating and communicating the historical-architectural heritage received by the University of Padua in the form of donations or acquisitions, the research project started by an interdisciplinary team coordinated by Elena Svalduz as scientific director (Dbc), Andrea Caracausi (Disgea), Andrea Giordano (Dicea), Nicola Orio (Dbc), Stefano Zaggia (Dicea), involved some researchers (Antonio Calandriello, Simone Fatuzzo and Umberto Signori). The writer has dealt in particular with the enhancement project that is proposed here.

[2] The software used for image processing was Agisoft Metashape Pro.

[3] https://www.momento360.com

[4] https://sketchfab.com. .

\section{References}

Basso Alessandro (2020). Ambienti virtuali per nuove forme di comunicazione. Virtual enviroments for new media. Roma: Aracne Editrice.

Bourdot Patrick, Interrante Victoria, Kopper Regis, Olivier Anne-Hélène, Saito Hideo, Zachmann Gabriel (eds.) (2020). Virtual Reality and Augmented Reality. Cham: Springer International Publishing.

Greengard Samuel (2019). Virtual Reality. Cambridge, Massachusetts; London, England:The MIT Press.

loannides Marinos, Fink Eleanor, Brumana Raffaella Patias Petros, Doulamis Anastasios, Martins João, Wallace Manolis (eds.) (20 I). Digital Heritage. Progress in Cultural Heritage: Documentation, Preservation, and Protection. Cham: Springer International Publishing.

loannides Marinos, Magnenat-Thalmann Nadia, Papagiannakis George (2017). Mixed reality and gamification for cultural heritage. Cham: Springer International Publishing.

Luigini Alessandro, Panciroli Chiara (20 I 8). Ambienti digitali per l'educazione all'arte e al patrimonio. Milano: FrancoAngeli.

Nespeca Romina (2018), Towards a 3D digital model for management and fruition of Ducal Palace at Urbino. An integrated survey with mobile mapping. In SCIRES-IT - SClentific RESearch and Information Technologies, 8 (2), pp. I - I 4.

Rossi Daniele (2020). Realtà virtuale: disegno e design. Roma: Aracne Editrice.

Sdegno Alberto, Masserano Silvia, Mior Denis, Cochelli Paola, Gobbo Eleonora (20I5), Augmenting painted architectures for communicating cultural heritage. In SCIRES-IT - SClentific RESearch and Information Technologies, 5 (I), pp. 93 - I 00.

\section{Author}

Antonio Calandriello, Dept. of Civil, Environmental and Architectural Engineering, University of Padua, antonio.calandriello@unipd.it 
